\title{
Gran's plots for end point detection in potentiometric titration of wine*
}

\author{
D. Rudan-Tasič and C. Klofutar \\ Department of Food Technology, Biotechnical Faculty, University of Ljubljana, SI-1000 Ljubljana, Jamnikarjeva \\ 101, Slovenia
}

\begin{abstract}
In several samples of Slovenian white wine the concentration of ethanol in extract, $\mathrm{pH}$ values, and total acidity were determined, as well as the densities and refractive indices. Total acidity was determined by a classical procedure which is the accepted method of the American Society of Enologists and the AOAC, i.e. the titration of wine with a strong base up to the titration "end point" at $\mathrm{pH}$ 8.2. In order to find the true end point, Gran's graphical procedure was employed and some examples of its practical application are illustrated. A Gran's plot converts a logarithmic response to a linear plot and it is shown that in spite of the complex wine matrix, this analytical procedure enables a precise, reproducible and accurate determination of the total acidity of wine.
\end{abstract}

Key words. Wine - total acidity - potentiometric titration - graphical procedure.

\section{Introduction}

The acid content of a wine is of importance from the standpoint of flavour and, indirectly, by its effects on $\mathrm{pH}$, colour, stability, and shelflife of the product. The acid levels are influenced by variety, climatic conditions, cultural practices, and the maturity of the grapes. The total (titratable) acidity is used during processing and finishing operations to standardize wines and to follow undesirable changes due to bacteria, yeasts, etc. The acids present in wines (tartaric, malic, citric, acetic, succinic, and lactic are common) are relatively weak organic acids. Thus when musts or wines are titrated with a strong base, the true end point will be greater than 7.0 on account of hydrolysis of the salts. Moreover, the total acidity, determined by potentiometric titration to the agreedon end point of $\mathrm{pH} 8.2[1,2]$ seems to be low as well. Above all, the $\mathrm{pH}$ value at the end point, $\mathrm{pH}_{\mathrm{e}}$, cannot be exactly of a unique value for all wines; it changes with acid composition and concentration [3]. The purpose of this study was to find out a precise, reproducible and quick method for determination of the total acidity of wine and to show the discrepancy between the real $\mathrm{pH}_{\mathrm{e}}$ and the normative value of 8.2 or even 7.0 .

\section{Experimental}

\section{Sample preparation for analysis}

Twenty samples of Slovenian wine (samples 1 to 8 were white and dry, samples 9 to 20 were white and medium dry, see Tabs. I and II) were just filtered (for density and refractive index measurements) or they were filtered and then $\mathrm{CO}_{2}$ was removed (for potentiometric analysis) by rapid heating of the sample up to the boiling point (half a minute). After the gas has been removed the sample was cooled quickly to $298 \mathrm{~K}$.

\section{Density measurements}

Density measurements were carried out using an A. Paar digital densimeter (model DMA 100) at a temperature of $298.15 \pm 0.02 \mathrm{~K}$. The densimeter was calibrated with water [4] and dry air [5]. The ethanol and extract content was determined by procedures given in the literature [6] and [7].

\section{Refractive index measurements}

Refractive indices were measured at $298.15 \pm 0.05 \mathrm{~K}$ with a Carl Zeiss Abbé refractometer (32-G 110e) with a precision of $1 \cdot 10^{-4}$ at a wavelength of $589 \mathrm{~nm}$.

\section{pH measurements}

$\mathrm{pH}$ values of the wines themselves, as well as changes during potentiometric titration were recorded using a $\mathrm{pH}$ meter (Radiometer, type PHM250 Ion Analyzer) with a glass combined electrode (Radiometer, type C2401-8). The $\mathrm{pH}$ meter was standardized with four IUPAC standard buffers (pH range from 3 to $10,[8]$ ).

\section{Potentiometric titration}

Potentiometric titrations of wine samples with a standard solution of sodium hydroxide $\left(c=0.1 \mathrm{~mol} \mathrm{dm}^{-3}\right)$ were performed in three parallel determinations in a titration vessel at $298.15 \pm 0.05 \mathrm{~K}$ by means of a digital burette (accuracy \pm $0.01 \mathrm{~cm}^{3}$ ). To reduce the concentration of ethanol and accordingly its influence on solvent and solute properties (e.g. changes in their activity coefficients), an aliquot of $5 \mathrm{~cm}^{3}$ of wine sample was diluted with $100 \mathrm{~cm}^{3}$ of boiled (and cooled) deionized water for each potentiometric titration.

\section{Results and discussion}

Several methods can be used to determine the end point of a potentiometric titration. One problem with using 
derivatives [9] to find the end point is that titration data are most difficult to obtain close to the end point, because buffering is minimal and electrode response is sluggish. A Gran plot $[10,11]$ is a graphical method that allows us the use of data from before (or after) the end point to localize the end point. Moreover, the titration curve need not be symmetric about the equivalence point.

A volume $V$ of acid is titrated with a volume $v$ of a strong base of concentration $B$ in the galvanic cell the electromotive force of which is determined by means of a $\mathrm{pH}$-meter;

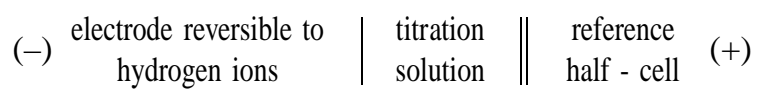

such a potential difference is given by

$$
E=E_{\mathrm{o}}^{\prime}-\frac{R T}{F} \ln \left[\mathrm{H}^{+}\right] \gamma_{\mathrm{H}^{+}}+E_{\mathrm{j}}
$$

where $E_{\mathrm{o}}^{\prime}$ includes the potential of the reversible and reference electrode, $E_{\mathrm{j}}$ is the liquid junction potential, $R$ is the gas constant, $F$ the Faraday constant, $T$ the absolute temperature, $\left[\mathrm{H}^{+}\right]$the molarity of free hydrogen ions and $\gamma_{\mathrm{H}^{+}}$the activity coefficient of hydrogen ions.

Because wine is a complex mixture of several weak acids, both mono and polyprotic ones, we used Gran's graphical method of end point determination for the alkaline range, i.e. after the equivalence point, $v_{\mathrm{e}}$. In this range, $v \geq v_{\mathrm{e}}$ and the concentration of hydrogen ions is given by the relation

$$
\left[\mathrm{H}^{+}\right]=\frac{K_{\mathrm{w}}}{\left[\mathrm{OH}^{\top}\right]}=\frac{K_{\mathrm{w}}(\mathrm{V}+\mathrm{v})}{B\left(\mathrm{v}-\mathrm{v}_{\mathrm{e}}\right)}
$$

where $K_{w}$ is the ionic product of water. Taking into account the relation for the activity of hydrogen ions, $a_{\mathrm{H}^{+}}=\left[\mathrm{H}^{+}\right] \gamma_{\mathrm{H}^{+}}=10^{-\mathrm{pH}}$ in equation (3) it follows

$$
\left[\mathrm{H}^{+}\right]=\frac{10^{-\mathrm{pH}}}{\gamma_{\mathrm{H}^{+}}}=\frac{K_{\mathrm{w}}(V+v)}{B\left(v-v_{\mathrm{e}}\right)}
$$

If $\mathrm{pH}$ is measured directly, we may make use of a function defined as

$$
\Phi^{\prime}=\frac{B\left(v-v_{\mathrm{e}}\right)}{K_{\mathrm{w}} \gamma_{\mathrm{H}^{+}}}=(V+v) \cdot 10^{\mathrm{pH}}
$$

Instead of $\mathrm{pH}$ the potential $E$ can be determined and, taking into account relations (2) and (3), it follows

$$
\left[\mathrm{H}^{+}\right]=\frac{K_{\mathrm{w}}(V+\mathrm{v})}{B\left(\mathrm{v}-\mathrm{v}_{\mathrm{e}}\right)}=\frac{1}{\gamma_{\mathrm{H}^{+}}} \cdot 10^{-\frac{E F}{2.303 R T} \cdot 10^{\frac{\left(E_{\mathrm{o}}^{\prime}+E\right) F}{2.303 R T}}}
$$

and we may use a similar function defined by

$$
\Psi^{\prime}=(V+v) \cdot 10^{\frac{E F}{2.303 R T}}=\frac{B\left(\mathrm{v}-\mathrm{v}_{\mathrm{e}}\right)}{K_{\mathrm{w}} \gamma_{\mathrm{H}^{+}}} \cdot 10^{\frac{\left(E_{\mathrm{o}}^{\prime}+E_{\mathrm{e}} F\right.}{2.303 R T}} .
$$

If $\gamma_{\mathrm{H}}, E_{\mathrm{j}}$ and $K_{\mathrm{w}}$ remain constant throughout the titration, then from equations (5) and (7) the quantities $\Phi^{\prime}$ and $\Psi^{\prime}$ are linear functions of $v$, such that $\Phi^{\prime}(v), \Psi^{\prime}(v)$ and the abscissa all intersect at the point $0, v_{\mathrm{e}}$. Thus the value of $v_{\mathrm{e}}$ may be obtained by plotting any one of the quantities $\Phi^{\prime}$ or $\Psi^{\prime}$ against $v$, and extrapolating the line obtained to cut the abscissa at the point $v=v_{\mathrm{e}}$.

A Gran's plot $\Phi^{\prime}=\Phi^{\prime}(v)$ for the titration of wine sample 4 as well as the $\mathrm{pH}$ dependence from the volume of base added, $v$, is shown in figure 1 . Similar titration curves and Gran's plots were found for all other wine samples. They are all comparable to the potentiometric titration curve and Gran's plot of a model mixture of aqueous solutions of some organic acids (Fig. 2). All titration curves, the model and sample ones, were found to show only one inflection point because of the overlapping of several degrees of dissociation of organic acids. In the case of wine samples, indeed a small deviation from linearity near the equivalence point, $v_{\mathrm{e}}$ can be observed (Fig. 1). It may be due to different factors, e.g. contamination of the real sample with metal ions which form complexes with anions of acids, interference of dissolved carbon dioxide still present in wine sample, etc. But the beauty of a Gran's plot is that only a few points are needed on the straight line at some distance away from the end point. However, a perfect linear fit of the theoretical curve to the experimental points (see Fig. 1) enables us to find the end point in the potentiometric titration of wine samples in a very simple way.

In tables I and II the data for the wine samples investigated are presented. On the basis of the experimental results shown in table I, it is evident that the density of these wine samples is about $1 \mathrm{~g} \mathrm{~cm}^{-3}$, a value that is characteristic for dry wines [12]. Moreover, the lower values of refractive index for samples from 1 to 8 and the higher ones for samples from 9 to 20 indicate corresponding sugar contents, i.e. they confirm the samples are dry and medium dry, res-

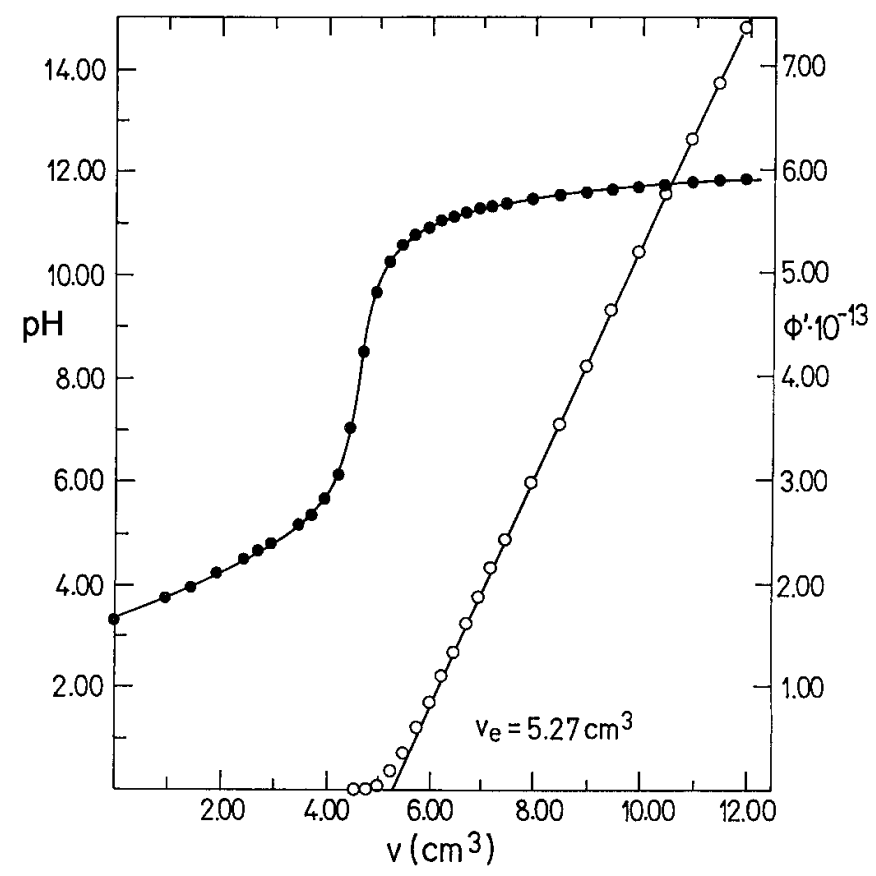

Fig. 1. Titration of $5 \mathrm{~cm}^{3}$ of wine (sample 4) $+100 \mathrm{~cm}^{3} \mathrm{H}_{2} \mathrm{O}$ with $\mathrm{NaOH}\left(c=0.1 \mathrm{~mol} \mathrm{dm}^{-3}\right)$. Change in $\mathrm{pH}$ and $\Phi^{\prime}$ with volume of base added, $v\left(\mathrm{~cm}^{3}\right) ; \mathrm{pH}_{\mathrm{e}}=10.26, c=0.1044 \mathrm{~mol} \mathrm{dm}^{-3}$. 


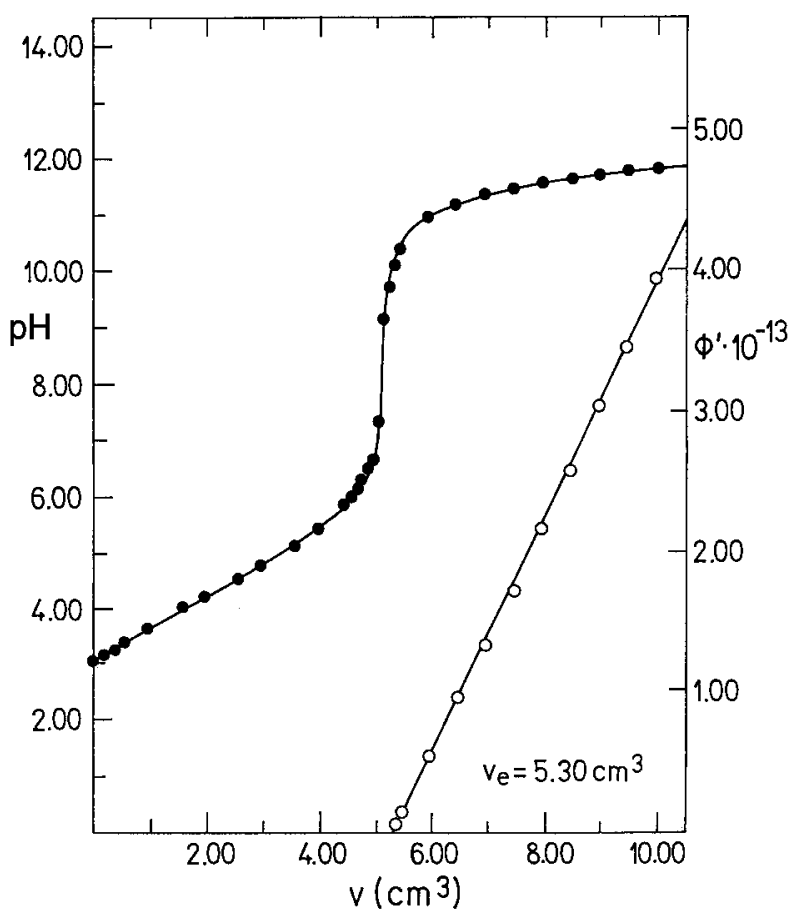

Fig. 2. Titration of $5 \mathrm{~cm}^{3}$ of model mixture (aqueous solutions of acetic, tartaric, malic, succinic and citric acid) $+100 \mathrm{~cm}^{3} \mathrm{H}_{2} \mathrm{O}$ with $\mathrm{KOH}\left(c=0.1 \mathrm{~mol} \mathrm{dm}^{-3}\right)$. Change in $\mathrm{pH}$ and $\Phi^{\prime}$ with volume of base added, $v\left(\mathrm{~cm}^{3}\right) ; \mathrm{pH}_{\mathrm{e}}=9.74, c=0.1055 \mathrm{~mol} \mathrm{dm}^{-3}$.
Table I. Density, refractive index, ethanol and extract content of several Slovenian white wine samples at $293 \mathrm{~K}$.

\begin{tabular}{lcccc}
\hline Sample & $\begin{array}{c}\rho \\
\left(\mathrm{cm}^{-3}\right)\end{array}$ & $\begin{array}{c}\text { ethanol } \\
(\text { vol. } \%)\end{array}$ & $\begin{array}{c}\text { extract } \\
\left(\mathrm{g} \mathrm{dm^{-3 }}\right)\end{array}$ & $n_{D}$ \\
\hline 1 & 0.99295 & 10.42 & 22.3 & 1.3417 \\
2 & 0.99163 & 11.39 & 21.9 & 1.3422 \\
3 & 0.99231 & 11.34 & 23.6 & 1.3424 \\
4 & 0.99119 & 12.24 & 23.5 & 1.3429 \\
5 & 0.99117 & 12.34 & 23.7 & 1.3430 \\
6 & 0.98920 & 12.17 & 18.0 & 1.3421 \\
7 & 0.99075 & 11.91 & 20.7 & 1.3424 \\
8 & 0.99112 & 12.26 & 23.2 & 1.3429 \\
9 & 0.99904 & 9.48 & 35.1 & 1.3430 \\
10 & 1.00071 & 10.74 & 43.3 & 1.3449 \\
11 & 0.99917 & 10.91 & 40.2 & 1.3445 \\
12 & 1.00053 & 11.00 & 43.8 & 1.3451 \\
13 & 0.99663 & 10.55 & 32.2 & 1.3432 \\
14 & 0.99779 & 10.82 & 36.1 & 1.3439 \\
15 & 0.99507 & 11.42 & 31.1 & 1.3435 \\
16 & 0.99606 & 11.55 & 33.5 & 1.3440 \\
17 & 0.99824 & 10.85 & 37.3 & 1.3441 \\
18 & 0.99690 & 11.64 & 36.4 & 1.3444 \\
19 & 0.99746 & 11.92 & 38.9 & 1.3449 \\
20 & 0.99616 & 12.00 & 35.7 & 1.3445 \\
\hline & & & &
\end{tabular}

Table II. Measures of wine acidity of various cultivars and locations in Slovenia at $293 \mathrm{~K}$.

\begin{tabular}{ccccccc}
\hline Sample & $p H_{\text {sample }}$ & $\begin{array}{c}c \\
\left(\mathrm{~mol} \mathrm{dm} \mathrm{m}^{-3}\right)\end{array}$ & $\mathrm{pH}_{e}$ & $\begin{array}{c}c^{*} \\
\left(\mathrm{~mol} \mathrm{dm} \mathrm{m}^{-3}\right)\end{array}$ & $\begin{array}{c}\left(\mathrm{c}-\mathrm{c}^{*}\right) \cdot 10^{3} \\
\left(\mathrm{~mol} \mathrm{dm} \mathrm{m}^{-3}\right)\end{array}$ & $\begin{array}{l}\text { Buffer capacity } \\
\left(\mathrm{mmol} / \mathrm{dm}^{3} / \mathrm{pH}\right)\end{array}$
\end{tabular}

\begin{tabular}{rcccccc}
\hline 1 & 3.121 & 0.1181 & 10.24 & 0.1091 & 9.0 & 52.6 \\
2 & 3.154 & 0.1042 & 10.22 & 0.0970 & 7.3 & 46.9 \\
3 & 3.463 & 0.1008 & 10.25 & 0.0896 & 11.2 & 45.2 \\
4 & 3.142 & 0.1055 & 10.26 & 0.0940 & 11.5 & 45.1 \\
5 & 3.198 & 0.1079 & 10.17 & 0.0981 & 9.9 & 49.7 \\
6 & 3.246 & 0.0929 & 10.19 & 0.0815 & 11.4 & 42.2 \\
7 & 3.230 & 0.0942 & 10.08 & 0.0867 & 7.5 & 42.2 \\
8 & 3.160 & 0.1104 & 10.13 & 0.1005 & 9.8 & 47.8 \\
9 & 3.192 & 0.1288 & 10.27 & 0.1133 & 15.5 & 55.4 \\
10 & 3.073 & 0.1566 & 10.16 & 0.1435 & 13.1 & 67.1 \\
11 & 3.010 & 0.1170 & 10.10 & 0.1080 & 9.0 & 51.9 \\
12 & 3.315 & 0.1314 & 10.28 & 0.1154 & 16.0 & 55.1 \\
13 & 3.101 & 0.1331 & 10.08 & 0.1239 & 9.2 & 58.0 \\
14 & 3.356 & 0.1289 & 10.24 & 0.1156 & 13.3 & 55.6 \\
15 & 3.089 & 0.1119 & 10.13 & 0.1011 & 10.8 & 47.1 \\
16 & 3.298 & 0.1220 & 10.22 & 0.1088 & 13.2 & 50.9 \\
17 & 3.581 & 0.1275 & 10.28 & 0.1136 & 13.9 & 55.9 \\
18 & 3.122 & 0.1368 & 10.25 & 0.1230 & 13.8 & 57.4 \\
19 & 3.178 & 0.1317 & 10.30 & 0.1109 & 20.8 & 54.1 \\
20 & 3.316 & 0.1096 & 10.26 & 0.0932 & 16.3 & 45.8 \\
\hline
\end{tabular}

$c$ - total acidity determined by potentiometric titration up to the true end point of $\mathrm{pH}_{\mathrm{e}}$

$c^{*}$ - total acidity determined by potentiometric titration up to $\mathrm{pH} 8.2$. 
pectively. The extract value follows the sugar content in wine samples, although in general, the major components in the extract of dry wines are glycerol and organic acids. The buffer capacities, presented in table II, were calculated on the basis of potentiometric data, i.e. from polynomial dependence (second degree polynomial) of volume of strong base, $v\left(\mathrm{~cm}^{3}\right)$ on $\mathrm{pH}$ of diluted sample. Buffer capacity was expressed as the number of millimoles of strong base per litter needed to produce a unit change in $\mathrm{pH}$ and can be seen to vary due to the season, location and cultivar.

On the basis of the data in Table II one can conclude that the total acidity of wine, that measures free $\mathrm{H}^{+}$plus any undissociated acids that can be neutralized by base, $c$, is significantly higher if it is determined on the basis of the true end point, $\mathrm{pH}_{\mathrm{e}}$ (which obviously varies with samples) than the total acidity, determined on the basis of the proposed end point $\mathrm{pH} 8.2$. The maximum difference, $\left(c-c^{*}\right)$ is $0.0208 \mathrm{~mol} \mathrm{dm}^{-3}$ which is by no means negligible.

The method we used for titratable acidity determination of wine samples (it can be also be applied to juice or must) was found to be quite simple, reliable and accurate enough $\left(\delta c=15 \times 10^{-5} \mathrm{~mol} \mathrm{dm}^{-3}\right)$ for use in research and routine wine analysis. Namely, Gran's plots are quicker than the conventional plots because fewer data points are required, and because electrode response is generally fast at the concentrations needed for extrapolation of measurements. The calculations are quick and easy. Finally, the end points obtained by a linear Gran's extrapolation are much more precise than those obtained by the differential method, especially if the titration curve is not symmetrical, as it is exactly the case for wine samples.

\section{References}

1. Ough, C. S.; Amerine, M. A. In: Methods for Analysis of Musts and Wines; John Wiley \& Sons, New York, 1988; pp 50-70.

2. Zoecklein, B. W.; Fugelsang, K. C.; Gump, B. H.; Nury, F. S . In: Wine Analysis and Production; Chapman \& Hall, New York, 1995; pp 76-88.

3. Klofutar, C.; Šmalc, A. In: Zbornik Biotehniške Fakultete Univerze E. K. v Ljubljani 1980, 36, pp 153-173.

4. Kratky, O.; Leopold, H.; Stabinger, H. In: Digital Densimeter of Liquids and Gases (Paar A, K G, A-8054) Graz.

5. Weast, R. C. In: Handbook of Chemistry and Physics; 62 Edn, CRC Press, Cleveland, 1981-1982, F9 - F11.

6. Müller, T.; Würdig, G. In: Dtsch Lebensm-Rundsch, 1981, 77, pp 55-59.

7. Schmitt, A. In: Tabellen für die Weinanalytik; Druckhaus Goldammer, Scheinfeld, 1974.

8. Bates, R. G. In: Modern Classics in Analytical Chemistry; American Chemical Society, Washington, 1970; pp 5- 12.

9. Skoog, D. A.; West, D. M.; Holler, F. J. In: Fundamentals of Analytical Chemistry (6 th edn); Saunders College Publishing, New York, 1992; pp 432-435.

10. Rossotti, F. J. C.; Rossotti, H. In: J. Chem. Educ., 1965, 42, pp 375-378.

11. Gran, G. In: Analyst 1952, 77, pp 661- 671. 